\title{
DE BIOGRAFIE VAN EEN OBJECT: PEDDEL 5307-2
}

Het werk van Pauline Lunsingh Scheurleer richt zich voor een belangrijk deel op het oude hindoe-boeddhistische Indonesië. Een van de hoogtepunten is ongetwijfeld het samen met Marijke Klokke geschreven Divine Bronze uit 1988 , waarin voor het eerst een poging wordt gedaan de diverse stijlen van hindoe-boeddhistische bronzen te onderscheiden. Dit standaardwerk biedt museumconservatoren, verzamelaars en handelaren een heldere analyse van oud Indonesische bronzen en ontbreekt in geen enkele serieuze studie over U1 dit onderwerp. Echter, één onderwerp was blijven liggen in Divine Bronze. Over hoe en waarom de bronzen verzameld waren, vindt men vrijwel niets in het boek. Wellicht is dit te verklaren doordat onderzoekers in die tijd vaak het gevoelige onderwerp van de verzamelcontext lieten liggen, wellicht ook gewoon omdat het onderzoek voor Divine Bronze zich bewust op andere vragen richtte. ${ }^{1}$ Er bestond simpelweg geen goede stijlanalyse van OudJavaanse bronzen, dus de auteurs vulden een hiaat in onze kennis dat hoognodig gevuld moest worden.

Pauline Lunsingh Scheurleer zou echter in haar latere carrière het onderwerp van de verzamelgeschiedenis voortvarend gaan aanpakken, toegespitst op hindoe-boeddhistische gouden sieraden en de grote Javaanse stenen beelden

U. die zich in Nederlandse collecties bevinden. Het meest recente artikel van haar hand bevat een overzicht van de ontdekking en waardering van de Indonesische hindoe-boeddhistische culturen in de koloniale tijd. ${ }^{2}$

Voorwerpen worden in de handen van een museummedewerker altijd getransformeerd: vaak tot kunst, maar ook wel tot neutrale, 'objectieve' getuigenissen van historische perioden of andere culturen. In het verleden leidden dergelijke transformaties in veel gevallen tot het vrijwel volledig negeren van de voorkeuren en het referentiekader van de verzamelaar en van de cultureel-politieke context waarin het voorwerp verzameld werd. De verzamelcontext is belangrijk omdat die cruciale informatie biedt voor de interpretatie van voorwerpen. Een voorwerp is nooit een 'objectieve' betekenisdrager van één 'ware' betekenis. Een voorwerp speelt altijd een rol in een menselijk netwerk van sociale relaties, vaak met een politieke lading. De relatie tussen de aanbieder van het voorwerp en de verzamelaar is een complexe relatie, waarin economische en politieke motieven een rol spelen. Het begrijpen van de cultureel gekleurde voorkeuren van de verzamelaar en de cultureel gekleurde, en wellicht ook marktgerichte, voorkeuren van de verkoper van een voorwerp, is essentieel voor een goede interpretatie van een voorwerp. En hoe staat het met de rol van 'middlemen', van mensen die tussen de verkoper en de koper in staan?

De recente literatuur over verzamelen wijst keer op keer op het belang van een evenwichtige waardering van het verzamelproces, en van de

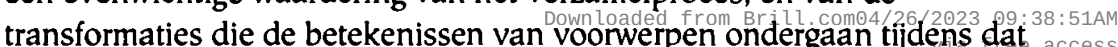



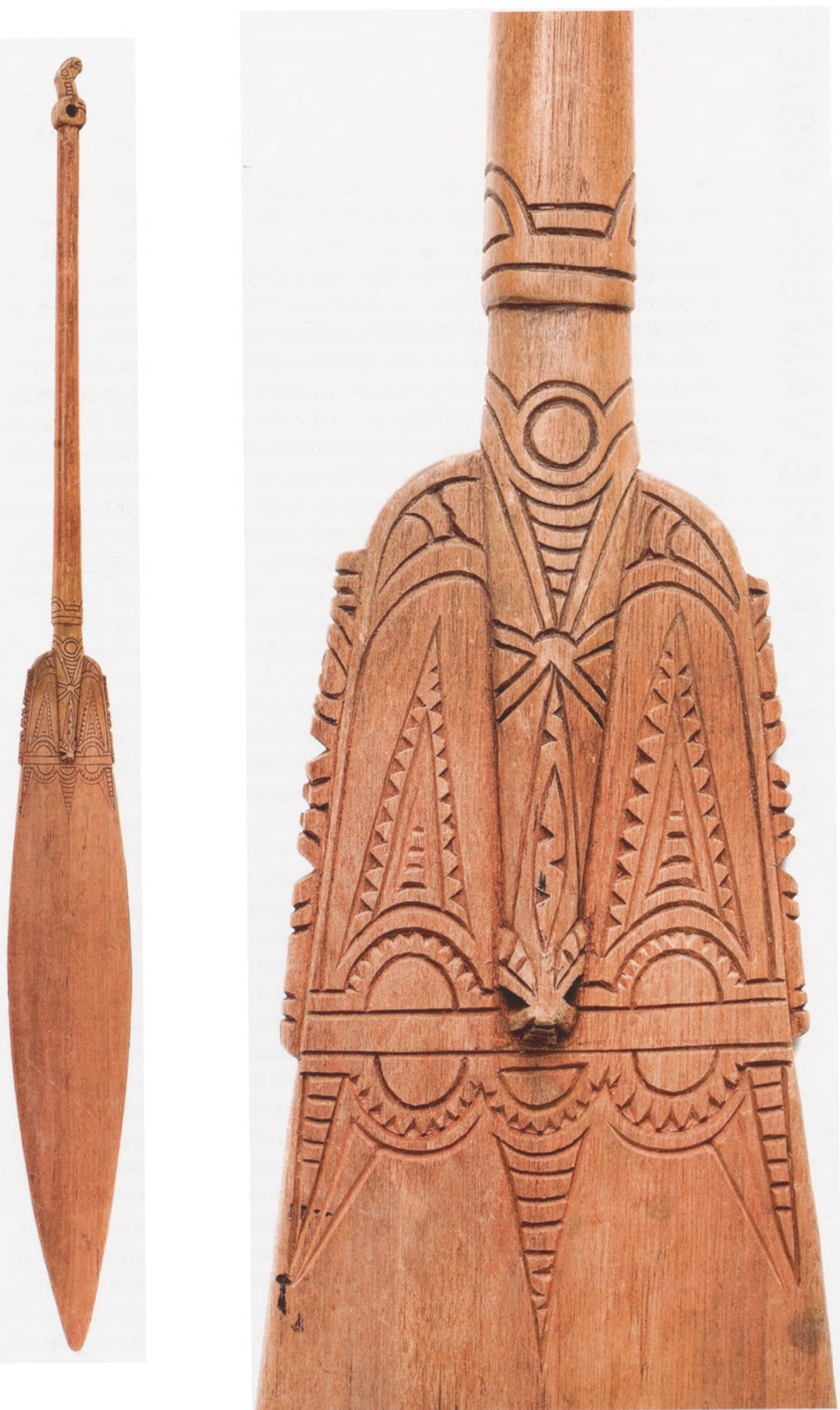

Downloaded from Brill.com04/26/2023 09:38:51AM via free access 
proces, omdat dat essentieel is voor het goed interpreteren van collecties en het voorwerp. ${ }^{3}$

\section{Afbeelding 1 (links) Peddel 5307-2, gemaakt door Sakail (Mandok, Papoea Nieuw-Guinea)}

Afbeelding 2
Detail van de peddel.
Hoewel Sakail niet veel
te melden had over de
motieven die hij uitge-
sneden had, sluiten ze
goed aan bij de traditi-
onele stijl van Siassi
houtsnijwerken. Vaak
worden mythische
wezens uitgebeeld die
mariam worden ge-
noemd. De ogen, neus
en neusgaten, waar de
steel overgaat in het
platte deel, zijn duidelijk
herkenbaar. Mariom
motieven worden regel-
matig gecombineerd
met slangachtige
motieven

Afbeelding 2 Detail van de peddel. Hoewel Sakail niet veel te melden had over de motieven die hij uitgesneden had, sluiten ze goed aan bij de traditionele stijl van Siassi houtsnijwerken. Vaak worden mythische wezens uitgebeeld die mariam worden genoemd. De ogen, neus en neusgaten, waar de steel overgaat in het platte deel, zijn duidelijk Mariom motieven worden regelmet slangachtige motieven
Het komt niet vaak voor dat een museummedewerker de transformatie vanaf de productie van een voorwerp tot aan de 'voorlopige' eindfase (het voorwerp in een vitrine met een lichtspotje erop of in het depot) van het begin tot het eind meemaakt. Bij oude hindoe-boeddhistische voorwerpen is dit helemaal niet mogelijk. De productiefase ligt in een tijd die voor ons slechts mondjesmaat toegankelijk is en het is dan ook niet verrassend dat archeologen en kunsthistorici die geïnteresseerd zijn in het oude Indonesië, moeite hebben met de productie en de eerste levensfase van een voorwerp. Kopytoffs invloedrijke oproep tot analyse van de 'culturele biografie' van het object is dan ook niet in alle omstandigheden te realiseren. ${ }^{4}$ Vaak ontbreekt de informatie. Daar komt in het geval van hindoe-boeddhistische oudheden nog eens bij dat ook de vroege verzamelgeschiedenis vaak slecht gedocumenteerd is. Meer dan eens werden beelden in de tuin van een koloniale ambtenaar gezet voordat ze voor het eerst door een serieuze wetenschapper werden gezien. Ook lokale verhalen over overblijfselen van vér verleden tijden werden vaak genegeerd. Want waarom zou een islamitische samenleving nog wat weten over hindoe-boeddhistische tempels en beelden? En, een nog hardnekkiger vooroordeel, informatie van lokale informanten zal wel niet echt betrouwbaar zijn! De legpuzzel van 'het leven' van een bronzen beeldje uit de $10^{\mathrm{e}}$ eeuw is helaas niet meer volledig te maken. Dit is anders bij sommige etnografische voorwerpen. Ik zeg met opzet 'sommige', want de meeste 'levensbeschrijvingen' van etnografische voorwerpen gaan net zo mank aan gebrek aan informatie als die van archeologische voorwerpen. Ook de meeste etnografische voorwerpen komen uit een onbekend, vaag verleden. Vaak heeft dat verleden een mythisch karakter, al was het alleen maar omdat de Westerse onderzoeker/verzamelaar een mooi, gekleurd verhaal opgetekend heeft om zijn (bijna nooit 'haar') daden te vereeuwigen. Een enkele keer echter kunnen we de biografie van een object vrijwel volledig volgen. Dat is onder meer het geval bij Peddel 5307-2, momenteel onderdeel van de collectie van Museum Volkenkunde in Leiden.

Peddel 5307-2 is verworden tot een nummer, een onpersoonlijk ding in een van de vele kasten in een museumdepot. Dat is echter niet altijd het geval geweest. Allereerst is de peddel onderdeel geweest van het leven van de maker, Sakail, die ongetwijfeld routinematig het snijwerk verricht heeft dat tot het ontstaan van dit voorwerp leidde. Houtsnijden was en is routine voor de meeste mannen in Sakail's dorp Mandok, in Papoea Nieuw-Guinea. Het is als het ware geïnternaliseerd in hun dagelijkse bezigheden. Het is voor de mannen van Mandok net zo normaal als fietsen voor ons Nederlanders. Mandok is de naam van een dorp en tegelijkertijd een eiland ten oosten van Nieuw-Guinea en het is onderdeel van de Siassi-eilanden, een archipel van voornamelijk lage koraaleilanden die de verbinding vormen tussen NieuwGuinea en Nieuw-Brittannië. Handel drijven met die twee grote eilanden is dan ook een belangrijke economische activiteit van de bewoners van Mandok. En houtsnijwerken zijn daarbij belangrijke handelswaar. Een groot deel van de eigen productie wordt voor de handel gemaakt. Het werd dan ook niet als iets vreemds ervaren toen ik op 24 september 1983 aan Sakail vroeg of ik de peddel kon kopen die hij net had gemaakt. 
Ik was pas enkele dagen op Mandok en was nog bezig met het inrichten van mijn dagelijks leven. Een van de problemen was dat ik voor transport, zelfs voor kleine afstanden, nog erg afhankelijk was van anderen. De missionaris, pater F. Lenssen, had nog een oude kano liggen die ik mocht gebruiken, maar hij had geen peddel voor me. Die moest ik dus in het dorp zien te vinden. Sakail bood me de recent gemaakte peddel aan voor 20 kina, voor die tijd en die context een fors bedrag (toen ongeveer 70 gulden). Ik zei dat ik erover na zou denken, vooral omdat ik niet direct bij mijn eerste aankoop meteen de gevraagde prijs wilde betalen. Toch was die $24^{\mathrm{e}}$ september mijn eerste kennismaking met wat enkele dagen later mijn peddel zou worden. Op mijn eerste echte werkdag op Mandok (26 september 1983) kocht ik de peddel van Sakail voor 10 kina. Over de motieven die hij had uitgesneden had hij niet veel mee te delen: oogmotieven en verder wat vrije fantasieën.

In loop van mijn veldwerk bij de Siassi van Mandok zou ik een bijzondere relatie opbouwen met 'mijn' peddel. Hoewel ik vond dat Sakail een prachtig stukje werk geleverd had, kon ik de peddel niet apart leggen en isoleren in afwachting van zijn toekomstige rol als museumvoorwerp. Ik had hem nodig voor praktische zaken. De witte museumhandschoentjes moesten maar een paar maanden wachten. En inderdaad, mijn relatie tot peddel 5307-2 bleek een stormachtige te worden.

De kano die de missie mij ter beschikking had gegeven was geen beste. De uitlegger zat niet goed vast en ondanks reparaties bleef het een wat zwakke constructie. Het probleem was dat de uitlegger telkens weer scheef ging hangen, waardoor hij in het water hapte en de kano moeilijk te sturen was. Om die reden moest ik vaak de uitlegger aan de verkeerde kant laten uitsteken. Anders zou ik nauwelijks vooruitkomen, zeker met harde wind. Mijn peddel echter was geweldig. De Franse antropoloog Jean-Pierre Warnier zou later zijn ideeën over materiële cultuur in verband brengen met menselijke motoriek. ${ }^{5}$ En ik zou die ideeën herkennen in mijn strijd met de elementen (water en wind) bij de Siassi-eilanden. In het begin moest ik leren peddelen. Een locale informant initieerde mij in de techniek van het peddelen met een kano met uitlegger. Zelfs met een uitlegger die niet goed was bleek het mogelijk de kano te sturen. En het lukte me. Sakails peddel werd een deel van mij. Mijn motoriek, in termen van Warnier, paste zich aan aan de eisen van de peddel waardoor object en subject met elkaar versmolten. Op zee werden 'peddel' en 'ik' volkomen afhankelijk van elkaar. Dit is niet alleen academische mooipraterij. Ik ervoer ook de wederzijdse afhankelijkheid. Het was zelfs van levensbelang. Als ik van Mandok naar Por (het eiland waar de missiepost gevestigd was) peddelde, was het allemaal niet zo spannend. Die twee eilanden lagen dicht bij elkaar en ik hoefde geen open zee op. Maar als ik de bescherming van de eilanden moest verlaten, was het van levensbelang om niet meegesleurd te worden door de wind, de stroming en de golven. Misschien overdrijf ik, maar ik had wel degelijk een sterk gevoel van gevaar, vooral bij harde wind. Eén keer had ik het bijna niet onder controle. Ik was moe en had ook een beetje koorts toen ik met harde wind van Mandok naar Por voer. Hoewel het geen moeilijke route was, ging het toch bijna mis. Ik dreef steeds verder af en had geen kracht meer om te voorkomen dat $\mathrm{ik}$ steeds verder richting open zee verdween. En wat dan? Met een uiterste krachtsinspanning lukte het me toch om in de windschaduw van Por te komen en langzaam naar het eiland toe te kruipen. Ik kwam uitgeput aan, mijmerend over wat er gebeurd zou zijn als ik het niet had gehaald.

Een dag later, terug op Mandok, hoorde ik dat de locale bevolking medt de 

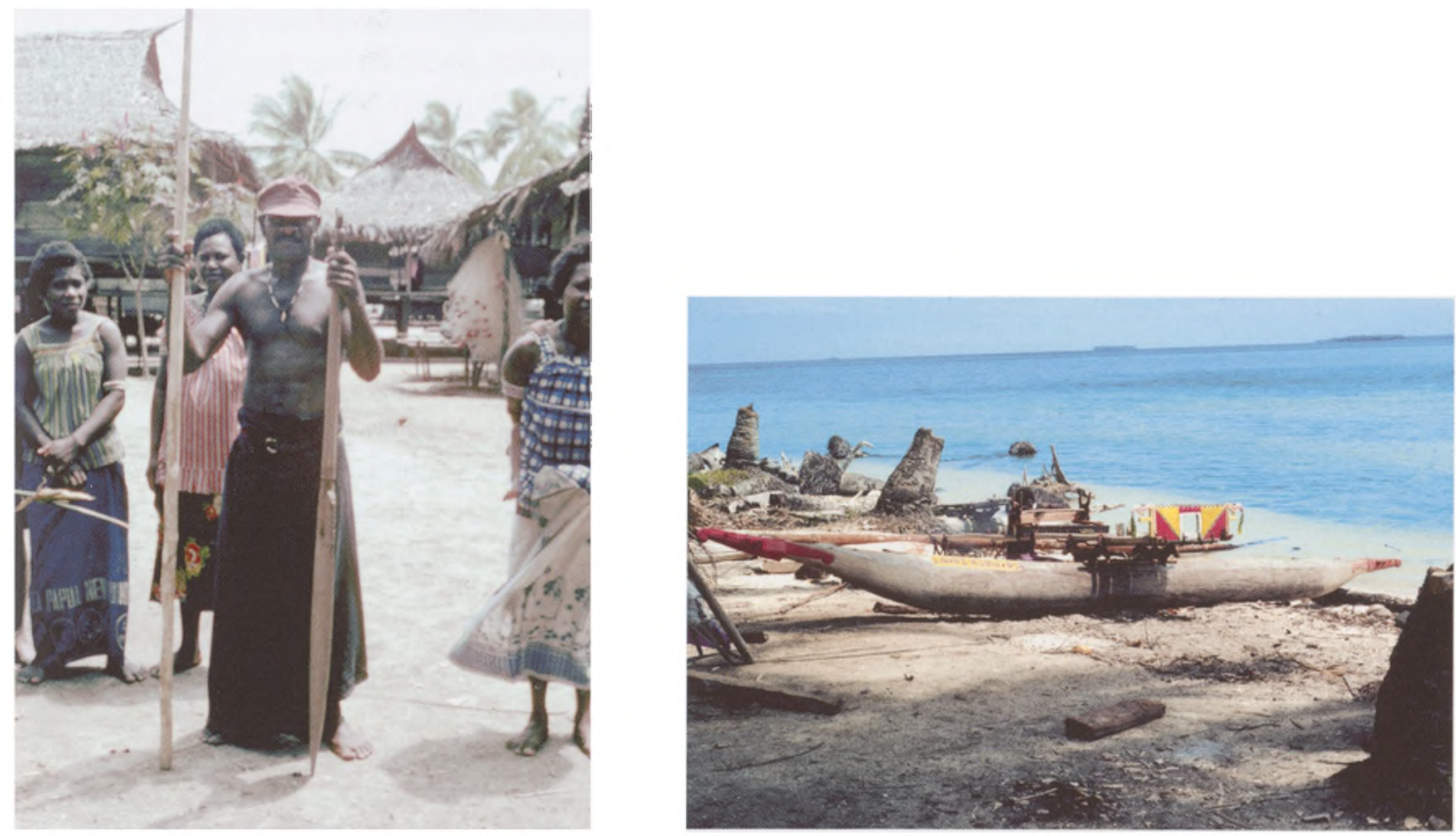

Afbeelding 3 (links) Sakail, de maker van peddel 5307-2. Hij poseert hier met de peddel en een vaarboom. Sakail is de zoon van familieleider Aibung, van wie hij het houtsnijden geleerd heeft

Afbeelding 4

Mandok is één van de belangrijkste productiecentra van kano's in het Siassi gebied. Op 8 oktober 1983 teide ik kleine en middelgrote kano's (wang gogon) in aanbouw gebruikelijke laconieke houding mijn geworstel had gadegeslagen (daar had ik niets van gezien) en had gedacht: 'laat hem maar lekker worstelen, als het niet lukt kunnen we hem altijd nog gaan helpen.' Zo overgeleverd aan de elementen was ik dus blijkbaar niet.

Door dit soort voorvallen werd de peddel echt ook 'mijn' peddel en ik kon mij goed voorstellen hoe mensen zich vergroeid kunnen voelen met een voorwerp. Dit geldt zowel in het veld als in een museale context. Onderzoek naar collecties in de depots kan in eenzelfde vervlechting tussen object en subject resulteren.

In januari 1984 keerde ik terug naar Nederland. Ik was toen nog niet in dienst van het Rijksmuseum voor Volkenkunde in Leiden, maar ik had toegezegd voor dit museum te zullen verzamelen. Enkele maanden later kwam het krat met voorwerpen in Leiden aan. Conservator Dirk Smidt en ik begonnen aan het uitpakken, catalogiseren en documenteren van de voorwerpen. Daarmee werd, paradoxaal genoeg, ook een begin gemaakt met het ontvlechten van de voorwerpen. De functies en betekenissen die werden genoteerd bevroren de voorwerpen tot één of enkele interpretaties en de ervaring en emotionele lading rondom de collectie verdween. Een enkele lezing kon dit proces niet verhinderen.

Mijn peddel was meegegaan in het kille proces dat plaatsvindt als we ons bewegen van veldsituatie naar museale context. Er was een nummer aan toegekend, 5307-2, en op de beschrijvingskaart valt te lezen dat Sakail niet zo veel te melden had over de motieven die hij gesneden had, maar dat de onderzoeker (ik dus) vermoedde dat hier uiteindelijk toch ook motieven waren uitgesneden die iets met de mythische wezens van de Siassi te maken hadden. De peddel was ondanks de beschikbare informatie uit het veld

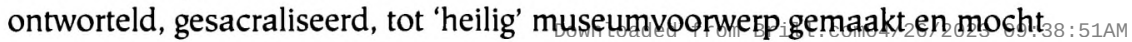
nu alleen nog maar worden aangeraakt met witte handschoenen. In' hef 'begiffess 
was ik mij nog niet zo bewust van de enorme transformatie die had plaatsgevonden, maar een jaar later werd ik ruw wakker geschud. Het museum organiseerde de tentoonstelling 'De Kilenge van Papoea Nieuw-Guinea' met foto's van Philip Dark en voorwerpen uit de eigen collectie. Mijn peddel werd in een vitrine geplaatst en er werd een spotje op gericht. Enkele dagen na de opening liep ik over de tentoonstelling te slenteren en hoorde een gesprek tussen twee cultuurminnende dames die uitgebreid 'mijn' peddel aan het bestuderen waren. De kunstzinnige aspecten van Sakails motieven werden breed uitgemeten en de esthetische 'discours' was lovend. Ik realiseerde me met een schok dat ik met die prachtige peddel had lopen gooien en dat ik meerdere malen mijn kano had vastgelegd door de peddel in de modder te steken tussen kano en uitlegger, hetgeen heel gebruikelijk is op Mandok. En voor het eerst had ik spijt dat ik 'mijn' peddel aan het museum gegeven had. Het was nu niet meer mijn peddel, het was nu verworden tot peddel 5307-2.

\section{Noten}

1. Kritische aandacht voor verzamelcontexten is pas in de jaren ' 90 van de $20^{e}$ eeuw een belangrijk onderdeel geworden van antropologische discussies.

2. P. Lunsingh Scheurleer, 'Collecting Javanese Antiquities; the appropriation of a newly discovered Hindu-Buddhist civilization', in: P. ter Keurs (red.), Colonial Collections Revisited, Leiden, 2007, pp. 71-114.

3. Het voert te ver om uitgebreid in te gaan op de recente wetenschappelijke discussies over verzamelen, in het bijzonder verzamelen in een koloniale context. In de jaren ' 90 verschenen diverse publicaties die kritische kanttekeningen plaatsten bij traditionele museale interpretaties van collecties. Een belangrijke mijlpaal was Nicholas Thomas' boek Entangled Objects; exchange material culture and colonialism in the Pacific, Cambridge, 1991.

4. I. Kopytoff, 'Cultural Biography of Things; commodification as process', in: A. Appadurai (red.), The Social Life of Things; commodities in cultural perspective, Cambridge, 1986, pp. 64-91.

5. J.P. Warnier, Construire la culture matérielle; l'homme qui pensait avec ses doigts, Parijs, 1999 en 'A praxeological approach to subjectivation in a material world', Journal of Material Culture 6/1 (2001), pp. 5-24. 